Kemper, J. W., Baggenstoss, A. H., and Slocumb, C. H. (1957). Ann. intern. Med., 46, 831 .

Kenney, J. D., and Calkins, E. (1965). Progress in Clinical Rheumatology, edited by A. St. J. Dixon, p. 281. Churchill, London.

Kreel, L., and Urquhart, w. (1963). Brit. \%. Radiol., 36, 715.

Laws, J. W. (1965). Progress in Clinical Rheumatology, edited by A. St. J. Dixon, p. 251. Churchill, London.

Lillie, J. G., and Scott, J. T. (1963). Brit. 7. Radiol., 36, 477.

Miall, W. E. (1955). Ann. rheum. Dis., $14,150$.

Osborne, G. V. (1957). 尹. Bone $\dot{f}_{t}$ Surg., 39B, 782

Palli (1959). Postgrad. med. 7., 35, 392.

Pallis, C. A., and Scott, J. T. (1965). Brit. med. F., 1, 1141
Schmid, F. R., Cooper, N. S., Ziff, M., and McEwen, C. (1961). Amer. f. Med., 30, 56 .

Sharp, J., and Purser, D. W. (1961). Ann. rheum. Dis., 20, 47.

Stuart, G. (1953). Private World of Pain, p. 20. Allen \& Unwin, London. Tait, G. B. W., Bach, F., and Dixon, A. St. J. (1965). Ann. rhe tim. Dis., 24, 273.

Thompson, M. and Leathart, G. L. (1965). Ibid., 24, 176.

Turner-Warwick, M., and Doniach, D. (1965). Brit. med. $\dot{\xi} ., 1,886$.

Vaughan-Jackson, O. J. (1962). 7 . Bone $7 t$ Surg., 44B, 764 .

Weintraub, A. M., and Zvaifler, N. J. (1962). Arthr. and Rheum., 5 327.

Zvaifler, N. J., and Weintraub, A. M. (1963). Ibid., 6, 241.

\title{
Syndrome of Encephalopathy and Fatty Degeneration of Viscera in New Zealand Children
}

\author{
D. M. O. BECROFT, * M.D., M.C.P.A.
}

Brit. med. F., 1966, 2, 135-140

In 1963 a new syndrome was described in Australian children based on the association of severe fatty degeneration of the liver with acute encephalopathy (Reye et al., 1963). Twenty-one children in Sydney had an acute illness with profound disturbance of consciousness progressing to coma, and, in the majority, to death within two and a half days of admission to hospital. Prodromal respiratory symptoms, persistent severe vomiting, disturbed respiratory rhythm, convulsions, altered reflexes and muscle tone, and hypoglycaemia were often present. Pronounced cerebral swelling and fatty changes in the kidneys were additional findings at necropsy.

In the correspondence which followed this first description similar cases were reported from England, Scotland, South Africa, and Czechoslovakia (Elliott et al., 1963 ; Maloney, 1963 ; Utian and Wagner, 1963 ; Stejskal and Kluska, 1964). Though this disease appears to be widely distributed the cause is unknown.

Since 1959 at least nine children in Auckland have died of a similar disease. The purpose of this report is to present the clinical and pathological features of these nine patients, to compare them with those previously described, and to consider possible aetiological factors. Three further cases of illnesses which possibly represent variations from the typical disease pattern are described.

\section{Typical Cases (Nos. 1-9)}

Six cases were seen in 1959 and 1960, and one in each of the years 1962 to 1964 . Ages ranged from $4 \frac{1}{2}$ months to $6 \frac{1}{2}$ years. Seven were less than 2 years old. There were seven boys and two girls. Four were European, three Polynesian, and two partPolynesian and part-European. All children had grown and developed normally. Two were siblings-brothers aged $1 \frac{1}{2}$ and $6 \frac{1}{2}$ years-whose illnesses occurred nine months apart. Otherwise there was no known contact between cases, no recent or past history of similar illnesses in the families, nor of other concurrent family illnesses. There was no particular seasonal incidence and no concentration of cases in one locality.

The major clinical, biochemical, and pathological findings are summarized in Table $I$ and details of individual patients are presented in Table II.

* Pathologist, Princess Mary Hospital for Children, Auckland, New Zealand.

\section{Clinical}

Coma was the major concern in all patients, and eight of the nine were unconscious or stuporous on admission to hospital. Most of them had prodromal symptoms. Six had a history suggestive of a trivial infection of the upper respiratory tract, usually with coryza and cough, beginning four to seven days previously. Repeated vomiting was a more dramatic symptom in six children, preceding the onset of coma by intervals of three days to a few hours. Though this vomiting was severe there was no haematemesis. It was accompanied by increasing drowsiness until coma ensued, without prior convulsions. Two children were irritable during the period of loss of consciousness, but only one had bouts of scręaming and violent movements similar to the wild delirium occurring in nearly half the cases described by Reye et al. (1963). Three children did not vomit. Two of these were the siblings who were found unconscious in bed in the morning, no previous symptoms having been noted. The third child had been admitted to hospital after a convulsion which appeared to be febrile in type. He had pharyngitis and otitis media, which settled promptly after treatment with tetracycline; but on the fifth day, after being anorexic for the previous 20 hours, he was found unconscious.

Seven patients had deep stertorous "acidotic" respirations shortly after the onset of coma. There was no evidence of shock, blood-pressures were normal, and there was minimal tachycardia. Only one child had a temperature above $38.5^{\circ} \mathrm{C}$. Six children had evidence of otitis media or pharyngitis. The only other findings of note at the initial examinations were a petechial rash on the abdomen and limbs of one child and moderate enlargement of the liver in another. There was no jaundice.

TABLE I.-Syndrome of Encephalopathy and Fatty Degeneration of the Viscera

\begin{tabular}{|c|c|c|c|}
\hline & $\begin{array}{l}\text { Essential } \\
\text { Features }\end{array}$ & $\begin{array}{c}\text { Usually } \\
\text { Accompanied by }\end{array}$ & $\begin{array}{l}\text { Less Frequently } \\
\text { Present }\end{array}$ \\
\hline $\begin{array}{l}\text { Clinical } \ldots \\
\text { Biochemical }\end{array}$ & $\begin{array}{l}\text { Acute severe progres- } \\
\text { sive disturbance of } \\
\text { cerebral function } \\
\text { ? }\end{array}$ & $\begin{array}{l}\text { Coryza and cough. } \\
\text { Vomiting. Hyper- } \\
\text { pnoea. Leucocytosis } \\
\text { Hypoglycaemia. } \\
\text { "Acidosis" }\end{array}$ & $\begin{array}{l}\text { Ketosis. Rising } \\
\text { blood urea }\end{array}$ \\
\hline Pathological & $\begin{array}{l}\text { Intense diffuse fatty } \\
\text { change in liver. } \\
\text { Cerebral swelling. } \\
\text { Absence of specific } \\
\text { findings }\end{array}$ & $\begin{array}{l}\text { Fatty change in renal } \\
\text { tubules. } \\
\text { Reactive changes in } \\
\text { lymphoid tissue }\end{array}$ & $\begin{array}{l}\text { Fatty infiltration of } \\
\text { myocardium. } \\
\text { Gastro-intestinal } \\
\text { haemorrhage }\end{array}$ \\
\hline
\end{tabular}


Coma deepened despite various forms of therapy, which included antibiotics, sedatives, adrenal steroids, and intravenous fluids, electrolytes, and glucose. No one medication was given to all patients. Eight developed focal twitchings and there were generalized convulsions in four. Increased muscular tone, clonus, or opisthotonos was recorded in the majority, and in two the terminal state was described as that of decerebrate rigidity. There were no localizing nervous-system signs. After a variable interval respirations became irregular and then ceased, and, except where positive-pressure respirations were maintained, death occurred shortly afterwards. The interval between the onset of coma and death was 12 hours to $5 \frac{1}{2}$ days.

The usual provisional diagnosis was encephalitis, but in all cases the cytology and protein content of the cerebrospinal fluid (C.S.F.) were normal.

\section{Biochemical}

Hypoglycaemia.-This was a feature of the first few cases, and initially was regarded as an essential part of the syndrome. Eight children had blood-sugar levels (Somogyi method) of $30 \mathrm{mg}$. $/ 100 \mathrm{ml}$. or less, accompanied by low sugar levels in the C.S.F. In most patients it was the finding of a low sugar level in an otherwise normal C.S.F. that led to the estimation of the blood levels. The ninth case had a normal blood-sugar level on one estimation, made shortly after the onset of coma.

"Acidosis."-The serum $\mathrm{CO}_{2}$ content was low in seven patients, and in four the levels were less than $11 \mathrm{mEq} / 1$. No blood $p H$ determinations were made, and the early view that there was a severe metabolic acidosis present may be incorrect in those patients with hyperpnoea. On two occasions intravenous lactate did not give the expected reversal of this change. Ketonuria was present in four cases.

Azotaemia.-Increased levels of blood urea or plasma nonprotein nitrogen were found in seven cases. A rapid rise was observed over a few hours in two cases, and the levels were abnormal in all patients who had been in coma for more than six hours.

\section{Pathological Findings}

Fatty Changes in the Liver.-The uniformly bright yellow or orange-yellow colour of the livers at necropsy was a striking finding, which was unexpected in the clinical setting and first drew attention to the syndrome. The distribution of sudanophilic material had two consistent features. (1) The fat was present in small vacuoles within the parenchymal-cell cytoplasm, the nucleus was not distorted, and the cell not greatly enlarged. The latter feature correlated with the usual slightto-moderate liver enlargement. (2) The change was uniform in parenchymal cells through all parts of the liver lobules and in all sections examined, though a single layer of periportal cells appeared to be slightly less severely affected in some cases (Fig. 1). The fat content was not estimated chemically. There was no necrosis and only slight reactive change in parenchymal cells, no cholestasis, and no cellular reaction in the portal tracts.
Little or no glycogen could be demonstrated in alcohol-fixed tissues.

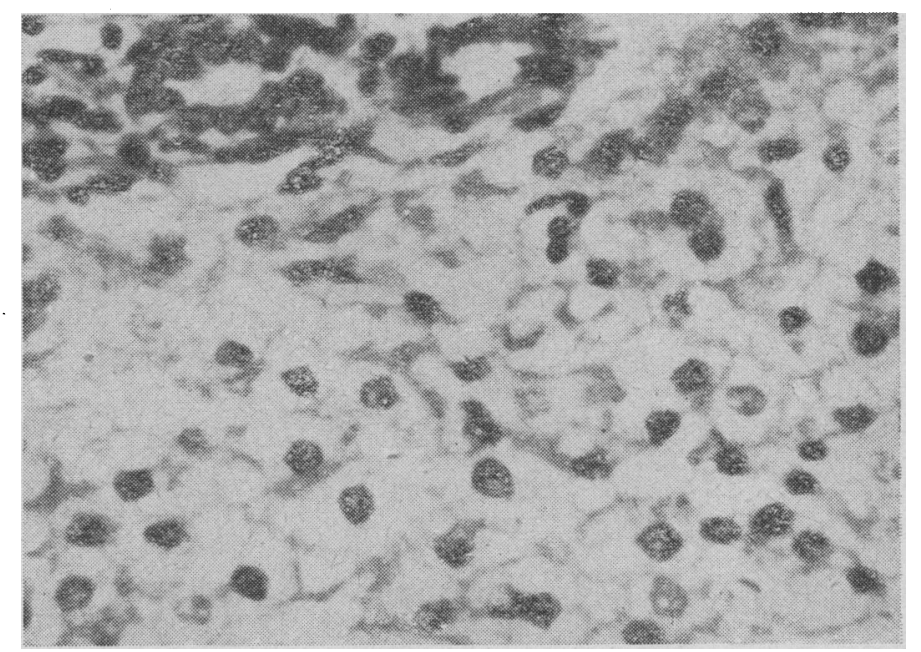

FIG. 1.-Photomicrograph of the fatty liver from Case 1. There is a uniform fine vacuolation of parenchymal cells. A bile duct is seen in the adjacent normal portal tract. (H. and $E$. $\times 460$.)

Cerebral Swelling.-In every case the brain was markedly swollen and oedematous. The gyri of the cerebral hemispheres were flattened but herniation of tissue was never pronounced. On microscopical examination non-specific anoxic changes in neurones and glia were found, similar to those described by Reye et al. (1963). There was no evidence of meningoencephalitis in more than 100 sections of central nervous tissue examined.

Other Organs.- The renal cortex was swollen and pale in eight patients. Frozen sections demonstrated abundant lipid in the cytoplasm of cells lining proximal convoluted tubules and to a less extent in the loops of Henle and distal convoluted tubules. No necrosis of tubules nor glomerular abnormalities were detected. In the majority of cases reactive changes were found in sections of lymphoid tissue. Lymphoid follicles had large pale central areas in which there were lipid-filled histiocytes and much karyorrhexis. The myocardium was mildly fatty in three cases. Three had altered blood within the stomach or intestine. Endocrine glands were normal macroscopically and microscopically, the examination in all cases including the serial slicing of the fixed pancreas. An early bronchopneumonia in one child was the only evidence of infection.

\section{Other Investigations}

Leucocytosis. -There was a neutrophil polymorphonuclear leucocytosis in six patients with total white-cell counts from 16,500 to $34,500 /$ c.mm.

Bacteriology.-Blood cultures in three cases and all cultures of C.S.F. were negative.

Virology.-Many specimens were inoculated into various culture systems, but no virus was isolated (Table III).

TABLE II.-Major Biochemical Findings

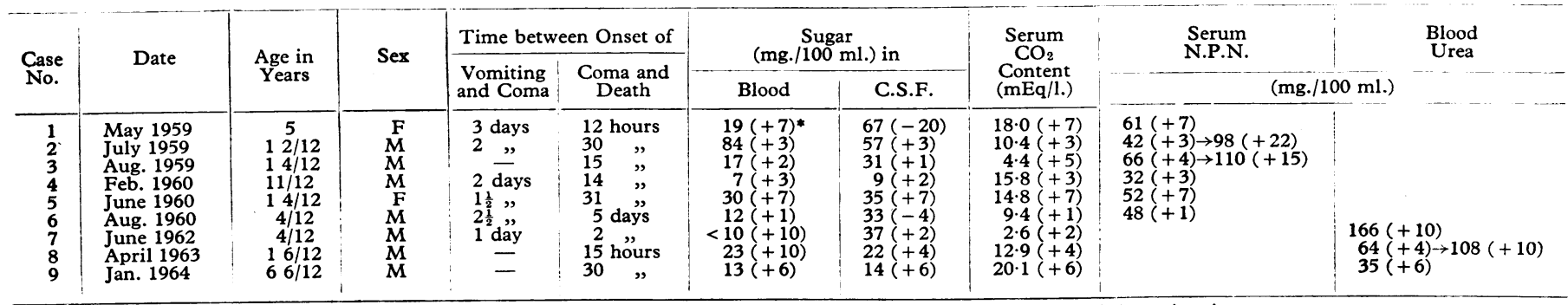


Chest $x$-ray films in seven patients were normal. An electroencephalogram in two cases showed a severe diffuse abnormality. Serum glutamic oxaloacetic transaminase (S.G.O.T.) levels of 95 and 70 Karmen units were found in two cases. Serum sodium was increased in two patients to 151 and 156 $\mathrm{mEq} / 1$. Serum bilirubin, calcium, salicylate, and proteins and urinary lead were each estimated in one or more patients and were normal.

\begin{tabular}{|c|c|c|c|c|c|c|c|}
\hline \multirow{3}{*}{\multicolumn{2}{|c|}{ Material }} & & \multicolumn{5}{|c|}{ Primary Inoculation (According to Case Number) } \\
\hline & & & \multicolumn{3}{|c|}{ Tissue Cultures } & \multirow{2}{*}{$\begin{array}{l}\text { Chick } \\
\text { Embryo }\end{array}$} & \multirow{2}{*}{$\begin{array}{l}\text { Suckling } \\
\text { Mice }\end{array}$} \\
\hline & & & $\begin{array}{l}\text { Human } \\
\text { Amnion }\end{array}$ & $\begin{array}{c}\text { HeLa or } \\
\text { Hep } 2\end{array}$ & $\underset{\text { Kidney }}{\text { Human }}$ & & \\
\hline $\begin{array}{l}\text { Brain } \\
\text { Liver } \\
\text { Spleen } \\
\text { Lung } \\
\text { Faeces } \\
\text { Throat s } \\
\text { C.S.F. } \\
\text { Blood }\end{array}$ & $\begin{array}{l}\ldots \\
\because \\
\ldots \\
\text { swab } \\
\ldots \\
\cdots\end{array}$ & $\begin{array}{l}\ddot{ } \\
\ddot{*} \\
\ddot{*} \\
\ddot{0} \\
\cdots\end{array}$ & $\begin{array}{l}3,4,6,7 \\
3,4,6 \\
3 \\
4,6 \\
4,6 \\
6 \\
4\end{array}$ & $\begin{array}{l}3,4,6,8 \\
3,4,6 \\
3 \\
6,8 \\
4,6,8,9 \\
4,6,9 \\
6 \\
4\end{array}$ & $\begin{array}{l}8,9 \\
9 \\
7,8,9 \\
9 \\
9 \\
=\end{array}$ & $\begin{array}{l}3,4,6,7 \\
3,4,6 \\
3- \\
4,6 \\
6-\end{array}$ & $\begin{array}{l}3,4,6,7,8,9 \\
3,4,6,9 \\
3 \\
7,8,9 \\
4,6,8,9 \\
9 \\
6 \quad-\end{array}$ \\
\hline
\end{tabular}

\section{Atypical Cases}

\section{Case 10}

A previously healthy 2-year-old European girl was admitted to hospital in September 1959. She had been irritable after a cold 10 days previously. On the day of admission she vomited repeatedly for several hours and became comatose. On admission she was not shocked and her temperature was normal. There was no acidosis or hypoglycaemia. After admission she had a generalized convulsion, but three hours later she was rousing and 10 days later appeared to be her normal self. She then vomited repeatedly for several hours and again became comatose. Blood-sugar levels were normal. Right-sided convulsions began and continued for three days. There was slow recovery, but she had residual right hemiparesis when she left hospital after one month. For one further month she appeared to be improving and had gained weight, then there was a sudden onset of continuous vomiting and retching lasting for 30 minutes and she became comatose. She remained in coma

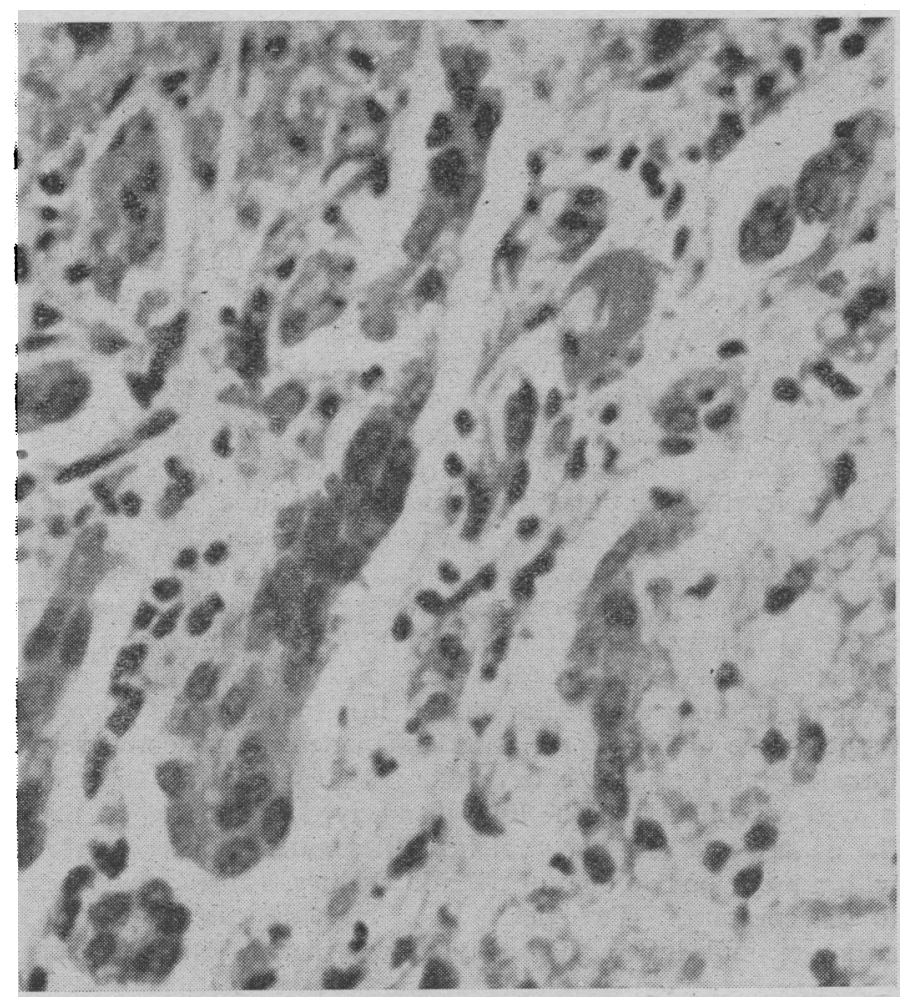

FIG. 2.-Photomicrograph of the fatty and cirrhotic liver from Case 10. The parenchymal cells resemble those in Fig. 1, but there is marked
bile-duct proliferation in the expanded portal tract. (H. and E. $\times 460$.) until her death seven weeks later. On each admission the C.S.F. was normal.

Necropsy showed that she was well nourished. The liver was bright yellow-orange in colour and finely nodular. Histologically there was extensive fibrosis, marked bile-duct proliferation, and patchy inflammation in the portal tracts (Fig. 2). The lobular pattern was disorganized and regenerative nodules were present. The majority of parenchymal cells contained large amounts of fat dispersed in small vacuoles, but a striking feature was the absence of this fatty change in the regenerative nodules. Conversely, stainable glycogen was restricted to these nodules. The brain weighed $900 \mathrm{~g}$. The greater part of the cortical grey matter was shrunken and finely cystic owing to extensive spongiosis. Histologically there was extensive gliosis and cyst-formation in the cortical grey matter, and slight demyelination and a lesser degree of gliosis in the white matter. Copper could not be demonstrated histochemically in the liver, cerebral cortex, and lenticular nuclei.

This patient had an unusual history with three episodes of coma preceded by vomiting, but not by convulsions. The first episode left no sequelae, the second left some cerebral defect, and on the third occasion the cerebral injury was severe. At no time was there clinical suspicion of liver disease, and the finding of cirrhosis was quite unexpected. The history and the character of the fatty change in the liver suggest a possible relation to Cases 1-9. The cirrhosis and encephalomalacia are likely sequelae of the acute lesions found in the latter patients.

\section{Case 11}

A $2 \frac{1}{2}$-year-old Maori girl was admitted to hospital in September 1964 with a history of cough, slight fever, vomiting, and diarrhoea since the previous day. For the previous 12 hours she had been drowsy, difficult to rouse, and hyperventilating. She had been a healthy child, though there had been convulsions with two previous respiratory infections. On admission she was comatose; respirations were stertorous, blood-pressure was normal, and temperature $35.3^{\circ} \mathrm{C}$. She was flaccid, reflexes were depressed, there was no meningism, and the ocular fundi were normal. Investigations: C.S.F. normal ; white blood-cells 36,000/c.mm. (neutrophils $68 \%$ ); blood culture negative; chest $x$-ray picture normal; blood sugar $94 \mathrm{mg} . / 100 \mathrm{ml}$.; serum sodium $137 \mathrm{mg} . / 100 \mathrm{ml}$.; serum $\mathrm{CO}_{3}$ content $4.4 \mathrm{mEq} / \mathrm{l}$. ; serum salicylate less than $5 \mathrm{mg} . / 100 \mathrm{ml}$.; blood urea $94 \mathrm{mg} . / 100 \mathrm{ml}$.

Treatment was started with penicillin, chloramphenicol, hydrocortisone, and intravenous bicarbonate. The acidosis proved refractory to large amounts of intravenous bicarbonate, and the next day blood $p \mathrm{H}$ was 7.19 and $\mathrm{PcO}_{2} 13.7 \mathrm{~mm}$. Hg. She remained unconscious, though there was some response to painful stimuli and return of reflexes. The liver became easily palpable and firm. The serum bilirubin and alkaline phosphatase levels were normal, but on the fifth day S.G.O.T. was 95 Karmen units, prothrombin time $41 \%$ of normal, serum beta-lipoproteins (method of Walton and Scott, 1964) $90 \mathrm{mg} . / 100 \mathrm{ml}$., and serum cholesterol $79 \mathrm{mg} . / 100 \mathrm{ml}$. Her condition then improved, but she became spastic and clearly had severe cerebral damage. An electroencephalogram showed a diffuse abnormality. Six weeks after the acute episode serum cholesterol and beta-lipoprotein levels had increased to 242 and $670 \mathrm{mg} . / 100$ $\mathrm{ml}$. respectively. The bromsulphalein excretion and urinary aminoacids were normal. After seven weeks she returned home, where she died shortly afterwards. Necropsy was not performed.

This patient had many features of the syndrome but is not included as a certain case because of lack of information on liver histology during the acute stage. The belief that the liver was abnormal is based on the clinical evidence of increasing size and abnormal firmness, on slight abnormalities of transaminase and prothrombin levels, and on the marked reduction in serum cholesterol and beta-lipoproteins during the acute stage (Walton and Scott, 1964).

\section{Case 12}

This previously healthy 10-month-old European girl was admitted to hospital in June 1963 with a history that on the morning of admission she appeared limp, later vomited twice, and then had two 
convulsions. On admission she was pale, limp, and comatose, though she responded to painful stimuli. Temperature $38.4^{\circ} \mathrm{C}$., blood-pressure $110 / 80 \mathrm{~mm}$. Hg. There were no localizing signs in the nervous system. The liver was palpable. Investigations: white blood-cells $21,200 /$ c.mm. ( $50 \%$ neutrophils); blood sugar less than $10 \mathrm{mg} . / 100 \mathrm{ml}$.; C.S.F. sugar $18 \mathrm{mg} . / 100 \mathrm{ml}$.; serum $\mathrm{CO}_{2}$ content $15.2 \mathrm{mEq} / 100 \mathrm{ml}$; serum sodium $151 \mathrm{mEq} / \mathrm{l}$.; serum potassium $5.1 \mathrm{mEq} / 1$. ; blood urea $41 \mathrm{mg} . / 100 \mathrm{ml}$, later rising to $174 \mathrm{mg} . / 100 \mathrm{ml}$. The C.S.F. had normal protein and no cells.

Treatment was with antibiotics, intravenous glucose, and $M / 6$ lactate. Some hours later she developed generalized convulsions and was vomiting altered blood. Respirations were deep and gasping until respiratory arrest occurred 30 hours after admission. Positivepressure respiration was maintained for three days until death. On the final day S.G.O.T. had increased to 1,020 Karmen units. Chest $x$-ray picture, electrocardiogram, serum proteins, alkaline phosphatase, and flocculation tests were all normal.

At necropsy there were severe fatty changes in the liver and nonspecific cerbral swelling identical to the findings in Cases 1-9. The adrenal glands showed microscopic foci of cortical necrosis, and adjacent cortical cells contained intranuclear eosinophilic inclusions. Herpes simplex virus was isolated from brain tissue (contamination from other organs was possible) and from a throat swab, but not from the C.S.F.

This patient would be included with the typical cases were it not for the isolation of herpes simplex and the presence of adrenal lesions to confirm a systemic infection by the virus. Otherwise the illness has no clear relationship to the infection. The lesions in the liver are not those usually associated with herpes infection, and early encephalitic changes were not detected (MacCallum et al., 1964).

\section{The Syndrome}

The individual components of the syndrome are not specific, and in various combinations are found in children with other illnesses of known or unknown cause. Nevertheless, when all features are considered, Cases 1 to 9 are believed to be distinct and to have some common aetiological or pathogenetic factor. The detailed histology of the liver is believed to be the most important criterion, and the essential features of uniformity of change throughout the liver lobules and the distribution of fat in small vacuoles have been reiterated by Reye and Morgan (1963). An identical histological appearance, with a somewhat similar clinical illness, occurs in the acute fatty liver of pregnancy, and the fact that some authors have regarded the changes as unique to pregnancy emphasizes the rarity of this particular pattern (Kahil et al., 1964).

The conclusions summarized in Table I were compared with those of Reye et al. (1963) before the published description of the Australian cases. Agreement was found on all major points (Reye, personal communication, 1963), strengthening the belief that this was a distinct disease entity. The differences between the two series were that in the Australian patients haemorrhagic phenomena, delirium, and excitability were more frequent, hypoglycaemia was not demonstrated in approximately onethird of cases, and high S.G.O.T. levels of between 126 and 1,170 units were found in all seven cases in which this was estimated.

Four patients reported from England almost certainly are further examples of the syndrome (Curry et al., 1962 ; Postgrad. med. F., 1962). The 16 patients in South Africa described by Utian et al. (1964) had an encephalopathy of acute onset, hypoglycaemia, metabolic acidosis, often accompanied by uraemia and hypernatraemia, and extensive fatty change in the liver. Though there is a similarity to the Auckland and Australian cases, no details were given of the histology of the fatty livers, neither vomiting nor gastro-intestinal haemorrhage was emphasized and cerebral oedema was absent at necropsy in 4 of the 11 cases examined. The "vomiting-sickness of Jamaica" is an illness of West Indian children in which vomiting is followed by coma, convulsions, and death in most cases. All eight cases of "vomiting-sickness" described by Hill et al. (1955) were hypoglycaemic. At necropsy the liver and kidneys were severely fatty and reactive changes were found in lymphoid tissue. The fatty changes in the liver had characteristics appropriate for the syndrome under discussion, and the "vomiting-sickness" appears to be a very similar, if not identical, disease.

Survival.-Certain diagnosis is difficult in a surviving patient because of the non-specific nature of many clinical features and because the most important criterion, the diffuse distribution of severe fatty change in the liver, cannot be established. Reye ct al. (1963) reported three cases in which the presumptive diagnosis was strengthened by the demonstration of fatty changcs in liver biopsies. These patients regained consciousness promptly, returned to normal health in a day or so, and remained well thereafter. Utian et al. (1964) described the cases of three patients who recovered, but these did not have liver biopsies, and two had permanent cerebral damage. No cases with recovery have been diagnosed with certainty in Auckland, largely because liver biopsies were not performed. However, Cases 10 and 11 may be examples of recovery from the acute stage, resembling the South African cases in that there was permanent brain damage.

\section{Aetiology and Pathogenesis}

The possibilities of infection and exposure to hepatotoxins have received major consideration in previous reports, but nutritional, endocrine, and genetic factors may be of importance. Little epidemiological information can be obtained from the various case reports. Though the disease has occurred sporadically, there was a peak in incidence in Auckland in 1959-60 and in Sydney in 1961. All cases in these reports have presented since 1950, and Reye et al. (1963) state that no similar cases were seen in their hospital in the preceding 10 years. Though the disease has occurred in several parts of Great Britain, it is uncommon at some large paediatric institutions (Corlett, 1963). Most of the patients have been infants aged 4 months to 2 years. Though there have been very few aged 2,3 , and 4 years, there is a small group of older patients, including one aged 13 reported by Utian et al. (1964). The sexes have been affected equally. The only connexion between cases appears to have been in two siblings in Auckland, but these illnesses were widely separated in time.

\section{Infection}

The diagnosis of septicaemia was made in early cases, but there was minimal pyrexia, no shock, and blood-cultures were negative. The prodromal symptoms have suggested a viral infection. The viral investigations performed in Auckland, although not systematic, largely exclude several common viral pathogens. There was systemic infection by herpes simplex in Case 12, but failure to demonstrate the virus in other patients appears to rule this out as a frequent association. Utian et al. (1964) favoured infection as a cause, and isolated a reovirus and a Coxsackie A virus from two patients. No viral investigations were carried out on the cases reported by Reye et al. (1963). If a viral infection is assumed, is this merely a precipitating factor, or is there a "target organ"? There have been no findings suggesting encephalitis in either the nervous tissue or the C.S.F. of the Auckland patients, and, conversely, fatty livers of this type have not been seen in histologically proved encephalitis. The liver histology does not suggest that the disease is a form of viral hepatitis, and complete recovery within a day or two of four cases in Sydney is further evidence to the contrary. Two possibilities, both difficult to exclude, although unlikely, are that an unknown virus might infect and alter metabolism in liver cells without causing cell necrosis, or that there is a distant infection by an organism producing a hepatotoxin (cf. diphtheria toxin). 


\section{Toxins and the Liver Lesions}

The characteristically diffuse distribution of fat in the liver suggests that the change is due either to some factor inherent in the cells or to some circulating agent. Many chemicals can produce fatty changes in the liver, which may be diffuse and without cellular necrosis. There may be accompanying hypoglycaemia. Poisoning was one of the first possibilities suggested by the liver pathology, and is still considered likely. There was no obvious history of exposure to toxins in early cases, and investigation of later cases in more detail has also been unrewarding. Reye et al. (1963) reported the negative results of two retrospective investigations in which the patients' environment was examined in detail for possible toxins, particular attention being paid to volatile agents and pesticides. The only positive finding in the detailed toxicological examination of the case described by Curry et al. (1962) was a bluefluorescent substance, tentatively identified as a pteridine, in the urine. The vomiting-sickness of Jamaica has been attributed to the effects of a vegetable poison, derived from one of the constituents of the "bush teas" brewed from indigenous plants (Hill et al., 1955).

Many patients have been infants less than 6 months old, and in these the possible sources of exposure to toxins are limited, but include the inhalation of volatile agents, contamination of foods, and improper medication. Any medicines given have been in amounts generally regarded as harmless. Hypersensitivity to a drug such as aspirin, an aetiology suggested by Giles (1965), is not excluded; although, so far as could be determined, several children were not given aspirin. Furthermore, the irregular and apparently recent occurrence of the syndrome does not correlate well with the common use of the drug. In two infants the possible dietary sources of toxin were limited to milk from the city supply, fresh vegetables, cereals, and canned baby-foods. The presence of significant amounts of a toxin in bulk milk supplies in Auckland appears most unlikely. Other foodstuffs, however innocent in appearance, cannot be easily dismissed. Recently interest has been shown in the contamination of foods with fungal toxins, stimulated by the occurrence of a lethal disease in poultry caused by products of Aspergillus flavus, the "aflatoxins" (Lancet, 1964). A number of blue- or green-fluorescent aflatoxins have been isolated (Sea Bong Chang et al., 1963). There has been speculation on the possible effects on man of aflatoxins and toxic products of other fungi which may contaminate cereals (Davidson, 1964 ; Brit. med. F., 1965). In the primate, under experimental conditions, aflatoxins initially produce severe diffuse fatty changes in the liver cells. In four weeks there is a fibrosis in the portal tracts and marked bile-duct proliferation accompanying the fatty change (Tulpule et al., 1964; Madhavan et al., 1965). There is a marked similarity between the early lesions described and illustrated by Madhavan et al. (1965) and those found in Cases 1-9 above, and the late lesions closely resemble those described in Case 10 . In calves aflatoxins can produce the experimental equivalent of veno-occlusive disease (Hill, 1964). As both veno-occlusive disease and the vomitingsickness of Jamaica have been attributed to the constituent of " bush teas" this provides a further interesting if tenuous link with the syndrome under discussion.

The possibility that fungal toxins might cause this syndrome emphasizes the need for future epidemiological studies to investigate apparently innocuous foods as potential sources of toxins. Aflatoxins are heat-stable and could be distributed in preserved foods, but in this event some additional factor, such as rare individual susceptibility, would be necessary to account for the sporadic occurrence of the disease.

Several mechanisms have been suggested for the production of fatty changes in the liver by hepatotoxins, but recent work supports the concept that inhibition of protein synthesis prevents the release of liver lipids to serum as lipoproteins (Rees and Shotlander, 1964). The marked reduction in serum beta- lipoprotein and cholesterol levels in Case 11 may be significant in this respect.

\section{Hormonal, Nutritional, and Metabolic Factors}

It is unlikely that the fatty liver and the severe metabolic disturbance are secondary to the encephalopathy, mediated either through hypothalamic-endocrine pathways or as a result of acute nutritional deprivation. Fatty liver is not commonly associated with other forms of diffuse brain disease in childhood. Chronic nutritional deficiency has been an associated factor in the "vomiting-sickness of Jamaica," but all cases of the present series were well nourished and deficiency of lipotrophic factors is most unlikely. There is no clinical or pathological evidence to suggest that an endocrine disturbance is the basis of the disease, but further information on circulating hormone levels would be of value in elucidating the pathogenesis of the hypoglycaemia and fatty changes in the liver (Gillman and Gilbert, 1958).

The hypoglycaemia is likely to be hepatic in origin, particularly as an association with fatty change is well recognized (Duncan, 1964). The absence of necrosis suggests that the biochemical lesion in the liver cells concerns special functions rather than cell viability. If the basic abnormality was a defect in gluconeogenesis then deprivation of exogenous glucose could lead to glycogen depletion, hypoglycaemia, mobilization of depot fat to the iiver, and ketosis. This sequence of events may account for the fatty livers and hypoglycaemia found in children with a congenital deficiency of the enzyme glycogen synthetase (Lewis et al., 1963 ; Parr et al., 1965), but in other respects such cases have differed from those under discussion. The hypoglycaemia accompanying the fatty changes in the liver produced by known hepatotoxins presumably results from separate effects on enzymes concerned with carbohydrate metabolism. Investigation of enzymes in liver tissue may reveal congenital or acquired deficiencies of this type in future cases.

\section{The Encephalopathy}

The later symptomatology and mode of death are those of progressive disease of the nervous system and are consistent with the effects of increasing intracranial tension. The available evidence is strongly in favour of this being an encephalopathy, initiated systemically, rather than an encephalitis. Histological abnormalitites in the brain are diffuse, non-specific, and of a type in which separation of true and artifactual change is of ten difficult. A number of known toxic and metabolic agents can produce similar changes, and identical appearances have been described in the brains of 16 children with acute encephalopathy of obscure origin, none of whom had fatty livers or hypoglycaemia (Lyon et al., 1961). Hypoglycaemia can produce similar pathological effects, and Utian et al. (1964) suggested that in their cases hypoglycaemia led to irreversible change in cerebral cells, thus accounting for the failure to respond to intravenous glucose. Although normal blood-sugar levels have been recorded in some cases, this does not exclude hypoglycaemia earlier in the illness. Intravenous glucose did not cause even transient improvement in the clinical state of patients in the Auckland series, and, although the encephalopathy is likely to have been hepatic in origin, hypoglycaemia probably was not the sole pathogenetic factor. Alternatively, a hepatotoxin may have had an independent toxic effect on the brain.

\section{Investigation of Future Cases}

The following suggestions are largely dependent on early diagnosis, which is made difficult by the sporadic occurrence of the disease and the non-specific clinical features.

1. Examination of the patient's environment for toxins, immediately rather than retrospectively, with particular attention to 
the possibility of toxins in apparently innocuous foods and medicines.

2. Further toxicological investigations, including analysis for fungal products, and examination of the urine for the fluorescent material described by Curry et al. (1962).

3. Further viral studies by all available techniques.

4. Chemical analysis of the liver and serum lipids, including estimations of serum lipoproteins.

5. Studies on liver enzymes, particularly those concerned with carbohydrate metabolism, preferably on biopsy rather than necropsy material.

6. Estimations during the acute stage of serum levels of adrenal corticoids, insulin, and growth hormone.

\section{Treatment}

Symptomatic treatment was unsuccessful in all Auckland patients. Reye et al. (1963) gained the impression that the use of corticosteroids and the continuous infusion of more than $2.5 \mathrm{~g}$. of glucose hourly gave improved chances of survival. As death appears to result from respiratory failure associated with raised intracranial tension, positive-pressure respiration will usually be indicated and hypothermia may be of value.

\section{Summary}

Since 1959 nine Auckland children have died from the disease first described under the title of "encephalopathy and fatty degeneration of the viscera." The constant features have been an acute severe progressive disturbance of cerebral function, a characteristically diffuse and uniform fatty change in the liver, and cerebral swelling. Prodromal coryza and cough, vomiting, hyperpnoea, leucocytosis, hypóglycaemia, low serum $\mathrm{CO}_{2}$ content, fatty changes in renal tubules, and reactive changes in lymphoid tissues have usually been present.

The late pathological effects are described in one of two atypical cases in which the patient survived the acute illness with residual cerebral damage. Another atypical case had a systemic infection by herpes simplex virus. Viral studies in other patients have been negative.

The aetiology is unknown but the effect of a hepatotoxin is thought to be most likely. Suggestions made for the investigation of future cases include the examination of apparently innocuous foods for hepatotoxins of fungal origin.

Dr. Alice Bush, Dr. R. H. Caughey, Dr. G. T. Fox, and Dr. W. R. Lang kindly gave permission for the publication of details of cases in their care. I wish to thank Dr. R. D. K. Reye, Professor Alex J. Steigman, and Professor M. C. Lancaster for helpful comments on these cases ; Dr. Selwyn Hills and Dr. J. F. Burton, in whose departments viral studies were performed; and Dr. P. J. Scott for estimations of lipoproteins.

\section{REFERENCES}

Brit. med. F., 1965, 1, 1261.

Corlett, K. '(1963). Lancet, 2, 937.

Curry, A. S., Guttman, H. A. N., and Price, D. E. (1962). Ibid., 1, 885. Davidson, C. S. (1964). Nutr. Rev., 22, 97.

Duncan, G. G. (1964). Diseases of Metabolism, 5th ed. Saunders, Phila-

Elliott, R. I. K., Mann, T. P., and Nash, F. W. (1963). Lancet, 2, 882.

Elliott, R. I. K., Mann, T. P., and Nash,

Gillman, J., and Gilbert, C. (1958). Brit. med. F., 1, 57.

Gillman, J., and Gilbert, C. (1964). Lancet, 1, 1280.

Bras, G., and Clearkin, K. P. (1955). W. Indian med. F., 4, 91.

Kahil, M. E., Fred, H. L., Brown, H., and Davis, J. S. (1964). Arch. intern. Med., 113, 63 .

Lancet, 1964, 1, 1090.

Lewis, G. M., Spencer-Peet, J., and Stewart, K. M. (1963). Arch. Dis. Childh., 38, 40.

Lyon, G., Dodge, P. R., and Adams, R. D. (1961). Brain, 84, 680.

Lyon, G., Dodge, P. R., and Adams, R. D. (1961). Brain, 84, 680 .
MacCallum, F. O., Potter, J. M., and Edwards, D. H. (1964). Lancet, Callum,

Madhavan, T. V., Tulpule, P. G., and Gopalan, C. (1965). Arch. Path., 79, 466.

Maloney, A. F. J. (1963). Lancet, 2, 1122.

Parr, J., Teree, T. M., and Larner, J. (1965). Pediatrics, 35, 770.

Postgrad. med. F., 1962, 38, 642 .

Rees, K. R., and Shotlander, V. L. (1964). Brit. F. exp. Path., 45, 364.

Reye, R. D. K., and Morgan; G. (1963). Lancet, 2, 1061.

Reye, R. D. Karal, J. (1963). Ibid., 2, 749.

Sea Bong Chang, M. M., Kader, A., Wick, E. L., and Wogan, G. N. (1963). Science, 142, 1191.

Steiskal, J., and Kluska, V. (1964). Lancet, 1, 615.
Tulpule, P. G., Madhavan, T. V., and Gopalan, C. (1964). Ibid., 1, 962.

Utian, H. L., and Wagner, J. M. (1963). Ibid., 2, 1010

Walton, K. W., and Scott, P. J. (1964). F. clin. Path., 17, 627.

\title{
A Brachiocephalic Vascular Syndrome Associated with Cervical Rib
}

\author{
J. C. DE VILLIERS,* M.D., F.R.C.S.
}

Brit. med. F., 1966, 2, 140-143

Cervical ribs may give rise to neurological or vascular syndromes. Virtually all reports concerning the vascular complications deal with the problem of arterial insufficiency in the upper limb. It is not widely appreciated that thrombosis in the right subclavian artery may extend proximally and give rise to cerebral embolism. This condition was first described by Gould in 1884, but Symonds (1927) was the first to offer the explanation that thrombosis in the right subclavian artery extended proximally to the point of junction of the right common carotid artery, and that portions of clot became detached, forming emboli to the cerebral circulation. In all, eight cases have been described with this syndrome, and details are summarized in the Table.

A similar syndrome associated with a traumatic aneurysm of the axillary artery due to an ununited fracture of the right

* Formerly Senior Registrar in Neurosurgery, Atkinson Morley's Hospltal, London. Present address: clavicle was reported by Yates and Guest (1928). In this patient an embolus into the basilar artery was proved at necropsy. Smith (1941) reported an axillary aneurysm with thrombosis extending proximally, and Wood (1941) described an aneurysm of the innominate artery with thrombosis and embolism giving an identical clinical picture to those cases with cervical rib.

\section{Case Report}

In February 1964 a girl aged 15 was found unconscious next to her bed in the early hours of the morning. She had a left hemiparesis, and was admitted to Atkinson Morley's Hospital for investigation. She had suffered from right-sided headaches associated
with nausea and vomiting for one year, and had been in almost continuous pain in the right arm and forearm for about three months. Later she developed pallor of the thumb and index finger and a "bruise" of the skin overlying the right first interosseus space. She had also had a chilblain on the right thumb for about two weeks. 